\title{
Development and validation protocol for an instrument to measure women's empowerment in urban sanitation across countries: The Agency, Resources, and Institutional Structures for Sanitation-related Empowerment (ARISE) Scales
}

Authors:

Sheela S. Sinharoy ${ }^{1}$, Amelia Conrad², Madeleine Patrick², Shauna McManus ${ }^{3}$, Bethany A. Caruso ${ }^{1}$

${ }^{1}$ Hubert Department of Global Health, Rollins School of Public Health, Emory University, Atlanta, Georgia, United States of America

${ }^{2}$ Gangarosa Department of Environmental Health, Rollins School of Public Health, Emory University, Atlanta, Georgia, United States of America

${ }^{3}$ Department of Biostatistics and Bioinformatics, Rollins School of Public Health, Emory University, Atlanta, Georgia, United States of America

Keywords: public health; statistics \& research methods; epidemiology

\section{Corresponding author:}

Sheela S. Sinharoy, PhD MPH

Hubert Department of Global Health

Rollins School of Public Health, Emory University

Mailstop 1518-002-7BB

Atlanta GA 30322, USA

Email: sheela.sinharoy@emory.edu

Phone: +1 4043984881

Word count, excluding title page, abstract, references, figures and tables: 3,964 
medRxiv preprint doi: https://doi.org/10.1101/2021.05.04.21256595; this version posted May 6, 2021. The copyright holder for this preprint (which was not certified by peer review) is the author/funder, who has granted medRxiv a license to display the preprint in perpetuity.

\section{Abstract}

Introduction: Despite an increasing emphasis on gender and empowerment in water, sanitation, and hygiene (WaSH) programs, no rigorously validated survey instruments exist for measuring empowerment within the WaSH sector. Our objective is to develop and validate quantitative survey instruments to measure women's empowerment in relation to sanitation in urban areas of low- and middle-income countries.

Methods and analysis: We are developing the Agency, Resources, and Institutional Structures for Sanitation-related Empowerment (ARISE) scales through a process that involves three phases: item development; scale development and initial validation; and scale evaluation and further validation. The first phase includes domain specification, item generation, face validity and content validity assessment, and item refinement. The second phase involves a second round of face validity and content validity assessment, followed by survey implementation in two cities (Tiruchirappalli, India and Kampala, Uganda) and data analysis involving factor analysis and item response theory approaches, as well as reliability and validity testing. The third phase involves a final round of face validity and content validity assessment, followed by survey implementation in three additional cities (Narsapur and Warangal, India; and Lusaka, Zambia) and statistical analysis using similar approaches as in Phase 2 for further validation.

Ethics and dissemination: Ethics approvals have been received from ethics boards in all study locations. The study team will share findings with key stakeholders to inform programming activities and will publish results in peer-reviewed journals.

\section{Article Summary}

\section{Strengths and limitations of this study}

- We employ rigorous methods to develop survey instruments, including testing and validating 15 scales, to assess domains of women's empowerment related to sanitation.

- Phased data collection is being carried out across five urban locations in South Asia and Africa to ensure that the survey instruments are valid and comparable across contexts.

- Our survey instruments are specific to women in urban settings; adaptation and further validity testing is needed to develop instruments that can be administered in other settings (e.g. rural, peri-urban) and with men.

- The survey instruments are focused on empowerment at the individual, household, and community levels; they do not assess empowerment in markets (e.g. across the sanitation value chain) or in relation to policies and formal governance. 
medRxiv preprint doi: https://doi.org/10.1101/2021.05.04.21256595; this version posted May 6, 2021. The copyright holder for this preprint (which was not certified by peer review) is the author/funder, who has granted medRxiv a license to display the preprint in perpetuity. It is made available under a CC-BY-NC-ND 4.0 International license .

\section{Introduction}

Despite significant investment and prioritization, improved water and sanitation access remain out of reach for large portions of the global population. Only $71 \%$ of the global population has access to safely managed water and only $45 \%$ has access to safely managed sanitation. ${ }^{1}$ Water, sanitation, and hygiene (WaSH) programs have postulated that improving water and sanitation access will lead to improved health, well-being, and empowerment of women. ${ }^{2-4}$ However, women's empowerment is a latent construct and therefore presents substantial measurement challenges. A number of survey instruments have been developed for measuring women's empowerment, either broadly or in specific sectors (e.g. agriculture). ${ }^{5}$ However, no rigorously validated survey instruments exist for use within the WaSH sector.

Our objective is to develop and validate quantitative scales to measure domains and sub-domains of women's empowerment in relation to sanitation in urban areas of low- and middle-income countries. We define a scale as a measure in which items' values "are caused by an underlying construct" ${ }^{6}$ The Agency, Resources, and Institutional Structures for Sanitation-related Empowerment (ARISE) scales will assess women's empowerment in relation to urban sanitation across 15 sub-domains of empowerment. The ARISE scales will provide researchers, practitioners, and policymakers with tools to improve the design of sanitation programs and policies, evaluate the impacts of interventions, and monitor progress towards global targets, such as the Sustainable Development Goals (SDGs). The scales will also enable examination of the relationship between domains of sanitation-related women's empowerment and sanitation access, sanitation behaviors, and other characteristics, such as caste and area of residence.

\section{Methods and Analysis}

Our process for developing the ARISE scales involves three phases: item development; scale development and initial validation; and scale evaluation and further validation (See Table 1).

Table 1: Overview of planned methods and analyses for the development of the MUSE Scales

Activity Procedures

Phase 1: Item development

1.1 Domain specification

We specified domains and sub-domains based on an existing conceptual model of empowerment and a systematic literature review.

1.2 Item generation

We developed candidate items for each sub-domain through a multi-step process, beginning with a systematic literature review and a parallel landscape analysis.

1.3 Face validity and

We assessed face validity through cognitive interviews (Cls) conducted in two sites content validity assessment (Tiruchirappalli, India and Kampala, Uganda) and content validity through evaluation by four expert reviewers. We also conducted key informant interviews (KIIs) for additional insight.

1.4 Item refinement We revised items based on field notes from Cls, KIls, and expert feedback, adding, Phase 2: Scale development and initial validation
2.1 Content validity We conducted $\mathrm{Cls}$ with respondents in Tiruchirappalli and Kampala to assess the refined assessment for new \& items. modified items

2.2 Survey participant selection in $\mathbf{2}$ sites

\begin{abstract}
We randomly sampled female participants ages 18+ in Tiruchirappalli and Kampala in purposively selected neighborhoods in coordination with BMGF-funded partners and local government.
\end{abstract}


medRxiv preprint doi: https://doi.org/10.1101/2021.05.04.21256595; this version posted May 6, 2021. The copyright holder for this preprint (which was not certified by peer review) is the author/funder, who has granted medRxiv a license to display the preprint in perpetuity. It is made available under a CC-BY-NC-ND 4.0 International license .

2.3 Survey implementation \& management in 2 sites

2.4 Statistical analysis
We trained enumerators who carried out tablet-based data collection with approximately 1000 women in each of the two sites. Teams also targeted up to 100 women per site for retesting.

\section{Phase 3: Scale evaluation and further validation}

We developed an analysis plan a priori, which included the following steps: $2.4 a$ ) initial item reduction; 2.4b) factor extraction and further item reduction using exploratory factor analysis (EFA); 2.4c) item reduction using item response theory (IRT); 2.4d) dimensionality confirmation using confirmatory factor analysis (CFA); 2.4e) measurement invariance assessment using multiple-group CFA and IRT; $2.4 \mathrm{f}$ ) scale scoring; $2.4 \mathrm{~g}$ ) reliability testing; and $2.4 \mathrm{~h}$ ) validity testing.

3.1 Content validity assessment for new \& modified items

3.2 Survey participant selection in three sites

3.3 Data collection \& management

3.4 Statistical analysis
We will conduct Cls with respondents in two additional locations to assess any items refined or added based on statistical analyses (2.4).

We will administer cross-sectional surveys to a validation sample in three cities. The sampling strategy, participant selection strategy, and inclusion criteria are the same as Phase 2.

We will conduct enumerator training and survey implementation using tablet-based data collection.

We will conduct EFAs and IRT on data from each site to evaluate any new items generated in Phase 2, and conduct CFAs to test the factor structures identified in Phase 2 using the same fit indices and criteria to assess model fit. We will test for measurement invariance at both the group and item level using multiple-group CFA and IRT methods; calculate the reliability coefficient; and test for convergent, discriminant, known-groups, and external criterion validity.

\section{Phase 1: Item development}

\subsection{Domain specification}

The domains and sub-domains of the scales are based upon the conceptual model of women and girls' empowerment developed by Van Eerdewijk et al. and adopted by the Bill and Melinda Gates Foundation (BMGF). ${ }^{7}$ Van Eerdewijk et al. define empowerment as "the expansion of choice and strengthening of voice through the transformation of power relations so women and girls have more control over their lives and futures." ${ }^{17}$ The conceptual model includes three domains of empowerment - resources, agency, and institutional structures - each with multiple sub-domains. ${ }^{7}$

Using this conceptual model, we conducted a systematic review of peer-reviewed literature related to empowerment in WaSH. Details of the methods and results of the systematic review are forthcoming. We developed sanitation-specific definitions for each sub-domain of empowerment, drawing on the conceptual model's definitions with adaptations informed by the literature and team member expertise (Table 2). Adaptations included removing the mention of "girls" and excluding the market and state subdomains of institutional structures, as well as laws and policies, to focus on adult women's empowerment at individual, household, and community levels. Of note, we identified and defined two additional sub-domains of empowerment relevant to sanitation from the systematic review: privacy and freedom of movement (within resources and agency, respectively). 
medRxiv preprint doi: https://doi.org/10.1101/2021.05.04.21256595; this version posted May 6, 2021. The copyright holder for this preprint (which was not certified by peer review) is the author/funder, who has granted medRxiv a license to display the preprint in perpetuity. It is made available under a CC-BY-NC-ND 4.0 International license .

\subsection{Item generation}

Through the systematic review and a parallel landscape analysis, we searched for existing instruments to measure each domain and sub-domain of empowerment. As we identified instruments, we collated and assessed them for potential use and/or adaptation in our scales. While the systematic review focused on peer-reviewed publications in WaSH, the landscape analysis included grey literature and was not restricted to the WaSH sector. The landscape analysis identified 62 instruments that had not been identified through the systematic review (Supplementary Table 1).

Candidate items were identified or created deductively, through a multi-step process. ${ }^{8}$ First, we identified broad topics that had emerged through the systematic review for each sub-domain of empowerment. We simultaneously compiled items identified in the systematic review and landscape analysis, organizing them by empowerment sub-domain. Where possible, we revised or adapted existing items to align with identified sub-domain-specific topics; most newly developed items were developed to fill gaps in emergent topics that existing items did not meet. Across all sub-domains, we allowed for some redundancy, formulating items to capture the same latent construct in different ways. Finally, we reviewed the item sets by sub-domain of empowerment, focusing on comprehensiveness and alignment with our operational definitions, and made revisions as needed. This resulted in $15 \mathrm{draft}$ scales, one for each sub-domain of empowerment. All scales had ordinal response options of "strongly disagree," "disagree," "agree," and "strongly agree"; frequency response options of "never," "sometimes," "often," and "always"; or, in the case of Freedom of Movement, "not at all," "only with accompaniment," "alone with permission," "alone if I tell someone," or "alone without telling anyone."

In addition, we developed six draft indices. An index, in contrast to a scale, does not represent a latent construct. Rather than having a shared cause in the form of an underlying latent construct, the items in an index together share an effect on a latent construct. ${ }^{6}$ We developed five indices to measure women's actual experiences in relation to the four sub-domains of agency (household-level decision-making, community-level decision-making, leadership, collective action, and freedom of movement). The sixth index was for safety and security, to measure women's awareness of actual experiences of sanitationrelated violence among women they know. In addition to providing valuable information on women's actual experiences, the indices also contribute to scale validation. We hypothesized that associations would exist between women's self-reported experiences (or awareness of others' experiences) and the corresponding sub-domains of agency, which would enable the assessment of construct validity of the scales.

Table 2. Sanitation-specific definitions for sub-domains of empowerment, by domain.

Sub-domain

Decision-Making
Leadership

Collective Action

Freedom of movement

\section{Sanitation-Specific Definition}

\section{Agency}

Women influence and make decisions about sanitation inside and outside the home. Women assume leadership positions, effectively participate, and support women's leadership in informal and formal sanitation initiatives and organizations.

Women gain solidarity and take action collectively on sanitation-related issues. Women have the autonomy to move freely to access sanitation facilities, collect water for sanitation-related needs, and/or attend forums on sanitation issues, and women have freedom of movement despite sanitation circumstances. 
medRxiv preprint doi: https://doi.org/10.1101/2021.05.04.21256595; this version posted May 6, 2021. The copyright holder for this preprint (which was not certified by peer review) is the author/funder, who has granted medRxiv a license to display the preprint in perpetuity.

It is made available under a CC-BY-NC-ND 4.0 International license .

\begin{tabular}{|c|c|}
\hline Bodily Integrity & $\begin{array}{l}\text { Women's control over their bodies and ability to access and use their preferred sanitation } \\
\text { location. }\end{array}$ \\
\hline Health & $\begin{array}{l}\text { Women's complete physical, mental, and social well-being as affected by sanitation options } \\
\text { and conditions; not merely the absence of disease or infirmity. }{ }^{9}\end{array}$ \\
\hline $\begin{array}{l}\text { Safety and } \\
\text { Security }\end{array}$ & $\begin{array}{l}\text { Women's freedom from acts or threats of violence (physical or sexual), coercion, harassment, } \\
\text { or force when accessing and using sanitation locations or engaging in sanitation-related } \\
\text { decision-making processes in the public sphere. }\end{array}$ \\
\hline Privacy & $\begin{array}{l}\text { Women's ability to maintain desired levels of privacy when accessing and utilizing sanitation } \\
\text { locations. }\end{array}$ \\
\hline $\begin{array}{l}\text { Critical } \\
\text { Consciousness }\end{array}$ & $\begin{array}{l}\text { Women's ability to identify and question how inequalities in power operate in their lives in } \\
\text { relation to sanitation access and decision-making processes, and to assert and affirm their } \\
\text { self-efficacy inside and outside of the household as it relates to sanitation. }\end{array}$ \\
\hline $\begin{array}{l}\text { Financial and } \\
\text { Productive } \\
\text { Assets }\end{array}$ & $\begin{array}{l}\text { Women's control over economic resources and long-term stocks of value such as land, for } \\
\text { the purposes of meeting individual and household sanitation needs. }\end{array}$ \\
\hline Time & Women's control over their time and labor spent on sanitation-related tasks and activities. \\
\hline Social Capital & $\begin{array}{l}\text { Women's relations and social networks that provide tangible and intangible value and } \\
\text { support, including those that enable them to complete sanitation-related tasks and activities. }\end{array}$ \\
\hline $\begin{array}{l}\text { Knowledge and } \\
\text { Skills }\end{array}$ & $\begin{array}{l}\text { Women's knowledge and skills related to sanitation (e.g. operation and maintenance of } \\
\text { sanitation facilities) and their abilities to apply those knowledge and skills. }\end{array}$ \\
\hline \multicolumn{2}{|r|}{ Institutional Structures } \\
\hline Norms & $\begin{array}{l}\text { Collectively held expectations and beliefs of how women and men should behave and } \\
\text { interact inside and outside the household, specifically with regard to (a) the division of labor; } \\
\text { (b) decision-making; (c) leadership; (d) collective action; and (e) freedom of movement. }\end{array}$ \\
\hline Relations & $\begin{array}{l}\text { The interactions and relations - including conflicts, support, hostility, and communication - } \\
\text { with key actors that shape women's sanitation-related experiences. }\end{array}$ \\
\hline
\end{tabular}

\subsection{Face validity and content validity assessment}

We assessed face validity and content validity (i.e., if items adequately measure the domain of interest) of the initial scales through two methods: cognitive interviews (Cls) and expert review. ${ }^{10}$ Due to the length of the scales, $\mathrm{Cl}$ guides were prepared separately for each of the three domains of empowerment (Agency; Resources; Institutional Structures).

Cls took place in two cities, Tiruchirappalli, India and Kampala, Uganda, in July and August 2019. These cities were selected by BMGF based on the presence of existing BMGF-funded Citywide Inclusive Sanitation (CWIS) programs and the strength of local partners. In each city, twelve interviewers were recruited, all with research experience and local language skills. Interviewers received a five-day training on the purpose of the research, key concepts and definitions of empowerment, $\mathrm{Cl}$ methods, ethics, and all aspects of the $\mathrm{Cl}$ guides, with time to practice and provide feedback on translations and phrasing.

Neighborhoods were purposively selected in each city with the goal of sampling from different wealth strata. We defined the study population a priori to be adult women (age 18 and older). With the support of local leaders (Uganda) and staff who had previously carried out data collection in these areas (India), the research team purposively sampled participants with the aim of having an equal distribution across three sub-groups to represent varied life stages: between ages 18-25 and preferably unmarried; between ages 25-40 and preferably married or living with a partner; and over age 40. A city coordinator and/or field supervisor was present throughout data collection to guide participant selection, monitor quality control, and provide feedback. 
medRxiv preprint doi: https://doi.org/10.1101/2021.05.04.21256595; this version posted May 6, 2021. The copyright holder for this preprint (which was not certified by peer review) is the author/funder, who has granted medRxiv a license to display the preprint in perpetuity. It is made available under a CC-BY-NC-ND 4.0 International license .

In each city, data collection teams - comprised of one interviewer and one note-taker - conducted Cls with 9-16 individuals per domain of empowerment. Interviews were conducted in the local language (Tamil in Tiruchirappalli and Luganda or English in Kampala). Participants were asked to "think aloud" about each survey item, and interviewers probed participants to assess understanding and relevance of each item and to identify opportunities for improving wording and translation. Responses were audio recorded and note-takers took detailed field notes. In addition to the women's empowerment items, data collection included questions on sociodemographic characteristics of the respondent and her household as well as on access to and behaviors related to sanitation.

Members of our team led daily debriefings with data collection teams and took detailed field notes on data collectors' reports of scale items that were difficult to administer or understand, confusing or missing response options, and other problems. Team members also kept detailed notes throughout the training, data collection, and debriefing processes to capture emerging issues and additional topics that should be included or excluded during scale revision.

Key informant interviews (KIIs) were also conducted with WaSH and gender experts in Uganda ( $n=13$ ) and India $(n=20)$ to provide additional contextual information and insight to inform the inclusion, exclusion, or addition of items. Key informants were selected with the assistance of local teams in each site and included representatives from government, non-governmental organizations, the private sector, and academia.

Finally, a panel of four expert reviewers evaluated candidate items. Each expert reviewer received the draft scales, our sanitation-specific definitions for each sub-domain of empowerment, and instructions and background information. They provided item-specific and overall comments and feedback.

\subsection{Item refinement and survey preparation for Phase 2}

We revised the scales based on field notes from the Cls, KIls, debriefings, and feedback from the expert reviewers. Revisions included eliminating, combining, and re-phrasing items. We also added new items where gaps had been noted, especially sanitation-specific menstruation items and items about interactions between individuals and sanitation service providers. In preparation for Phase 2, we added measures to assess the criterion and construct validity of each scale (Appendix 1).

\section{Phase 2: Scale development and initial validation}

\subsection{Content validity assessment for new and modified items}

Following refinement and revision of the scale, beginning in November 2019, trained data collectors (selected from among those who worked on Phase 1 of the study) conducted a second round of Cls with 12 individuals each in Tiruchirappalli and Kampala to evaluate newly added items and translations prior to broader survey implementation. Team members carried out rapid analysis of data from the Cls and revised the survey instruments as needed.

\subsection{Sample size and participant selection in Tiruchirappalli and Kampala}

Following revisions from Phase $2 \mathrm{Cls}$, cross-sectional surveys were administered to a sample of respondents in Tiruchirappalli and Kampala.

Consensus is lacking on optimal sample size for scale development. However, the literature suggests a range of 5-15 respondents per item. ${ }^{11-13}$ We aimed for each scale to have at least 15 responses per item. At the time of the calculations, our longest scale consisted of 61 items, requiring a sample size of 915 
medRxiv preprint doi: https://doi.org/10.1101/2021.05.04.21256595; this version posted May 6, 2021. The copyright holder for this preprint (which was not certified by peer review) is the author/funder, who has granted medRxiv a license to display the preprint in perpetuity. It is made available under a CC-BY-NC-ND 4.0 International license .

respondents. We rounded this number up to 1,000 respondents per city to allow for approximately $10 \%$ non-response and missing data. We aimed to re-administer the survey with $5-10 \%$ of participants ( $\mathrm{N}=50$ 100) per city to assess test-retest reliability.

As in Phase 1, we purposively selected neighborhoods in each city from low and moderate wealth strata, in coordination with CWIS partner organizations and local government. Specifically, partners provided lists of neighborhoods in each city and identified several priority areas for data collection. In Tiruchirappalli, our team worked with the CWIS partners to select priority slum neighborhoods and nonpriority middle-income neighborhoods. In Kampala, our team matched priority neighborhoods to other neighborhoods of similar population size and income level, using census data.

Participant selection followed a simple random sampling strategy, specifically a random-walk sampling method. Enumerators were instructed to walk in pairs through selected neighborhoods, with one enumerator working on each side of the street, and to knock on every third door. To be eligible, the respondent needed to be a woman age 18 or older who spoke Tamil (in India) or English or Luganda (in Uganda), who was mentally competent (demonstrated through understanding of the study description and consent), and had no hearing or speech impediments that would prevent comprehension or participation. If the selected household had an individual present who met the inclusion criteria and consented to participate, the enumerator would administer the survey.

Respondents were asked whether they would be willing to participate in the same survey a second time. Those who completed the full survey and agreed to participate again were re-visited within one month. We selected a one-month timeframe because several of the scales refer to "the past month," and we aimed to capture responses within an overlapping period to reduce the likelihood of a meaningful change in any domains of women's empowerment leading to changes in responses to survey items.

\subsection{Survey implementation and management in two sites}

In each site, twelve to fourteen female enumerators were recruited. As in Phase 1, enumerators completed five days of training covering key concepts of the study, research ethics, and logistics, with two days for interactive practice administering the survey to one another and talking through any challenges.

Enumerators first obtained oral (India) or written (Uganda) consent, then administered the full survey instrument. The survey instrument included all 15 scales and six indices, plus modules on demographics, water and sanitation access and behaviors, menstruation, and additional items to assess validity. Each site had at least one city coordinator and/or field supervisor who provided day-to-day supervision and quality control. Data collection lasted 24-30 days in each site in December 2019 and January 2020.

Data were collected using tablets with Ona software (ona.io). In each site, the survey was programmed in both English and either Tamil (India) or Luganda (Uganda). Field supervisors checked surveys for completeness at the end of each day. Data were then uploaded to a secure data storage platform.

\subsection{Statistical analysis}

Following initial data cleaning and management, we will randomly split the data into equal sub-samples for exploratory and confirmatory factor analyses. We will examine summary statistics for items, then follow an a priori analysis plan that includes elements of classical test theory and item response theory. The analysis plan involves the following steps: item reduction based on missingness, factor extraction, 
medRxiv preprint doi: https://doi.org/10.1101/2021.05.04.21256595; this version posted May 6, 2021. The copyright holder for this preprint (which was not certified by peer review) is the author/funder, who has granted medRxiv a license to display the preprint in perpetuity. It is made available under a CC-BY-NC-ND 4.0 International license .

item reduction based on item response theory, dimensionality confirmation, measurement invariance assessment, scale scoring, reliability testing, and validity testing. Factor analysis will be conducted using Mplus software; all other analyses will be conducted using SAS and R.

\section{4a Initial item reduction}

First, we will drop any items with cumulative missingness $>30 \%$ (including those for which respondents answered "don't know" or "not applicable"), with the exception of items related to menstruation. We anticipate that our sample will include women who are not menstruating for many reasons, including pregnancy, lactation, and not being of reproductive age.

\section{4b Factor extraction and further item reduction}

We will use the first random sub-sample to perform exploratory factor analysis (EFA) for factor extraction. EFA is appropriate because a factor structure has not been previously established for the items. ${ }^{14}$ To determine how many factors to extract, we will use parallel analysis and scree plots. ${ }^{15}$

We will run EFA models on each scale, using means- and variance-adjusted weighted least squares estimators, which are appropriate for items with ordinal response options. ${ }^{16}$ We will use oblique rotation to allow for correlation between the factors representing sub-domains of empowerment. ${ }^{14} 15$ We will examine model statistics from several types of oblique rotations to assess differences across methods and to choose an oblique rotation method. We will interpret model fit based on the following indices: Root Mean Squared Error of Approximation (RMSEA), Comparative Fit Index (CFI), Tucker-Lewis Index (TLI), and Standardized Root Mean Squared Residual (SRMR). RMSEA<.08, CFI>.95, TLI>.95, and SRMR<.06 are considered good fit. ${ }^{17}$

After running each model, we will drop items based on low pattern coefficients (i.e. $<|0.300|$ ), high multidimensionality (i.e. cross-loadings $(>|0.300|$ ) on two or more factors with a difference between loadings of $<0.20$ ), or significant negative pattern coefficients. We require a minimum of two items per factor and will remove items that load alone on a factor.

\section{$2.4 \mathrm{c}$ Item reduction using item response theory}

In addition to factor analysis, we will use item response theory (IRT) approaches to assess psychometric properties of individual items within each scale. We will use graded response models (GRM), which are appropriate for items with ordinal response options. ${ }^{18}$ We will evaluate the assumptions of local independence and functional form, and assess model-data fit visually and statistically. ${ }^{18}{ }^{19}$ Items identified as having local dependence will be considered for removal, as will items with poor item-level model-data fit. ${ }^{18}$ We will examine item properties, including item information curves (IIC) and option characteristic curves (OCC), also known in GRMs as item response category characteristic curves. ${ }^{180-22}$ We will calculate slope (discrimination) and threshold (difficulty) parameter estimates and visually examine IIC and OCC plots to assess item performance..$^{20-22}$ We plan to iteratively drop items and run the analysis with the remaining variables until a final model is reached.

\section{4d Dimensionality confirmation}

We will use confirmatory factor analysis (CFA) on the remaining random split-half sample to test the structures that were identified through the above process. We will use the same fit indices and criteria described above to assess model fit. 
medRxiv preprint doi: https://doi.org/10.1101/2021.05.04.21256595; this version posted May 6, 2021. The copyright holder for this preprint (which was not certified by peer review) is the author/funder, who has granted medRxiv a license to display the preprint in perpetuity.

\section{4e Scale scoring}

We will calculate sums and mean scores for each scale and used both unweighted (sum and mean) and weighted (factor scores) scores for subsequent validity assessments.

\section{4f Reliability testing}

To assess internal consistency, we will examine inter-item correlations and calculate the reliability coefficient, coefficient omega, which, unlike coefficient alpha, does not assume equal covariances of items with their common factor. ${ }^{23}{ }^{24}$ While consensus is lacking on thresholds for values of omega, we determined that 0.70 would be acceptable. ${ }^{25} 26$

In addition, we will assess test-retest reliability using data from the sub-sample of respondents who completed the survey twice within a one-month period. We assume that respondents' level of empowerment would remain stable during this timeframe and that changes in responses would only reflect the stability of our measure. We will estimate test-retest reliability by calculating intraclass correlation coefficients (ICCS) of scored scales. ICCs will be calculated with two-way mixed effect models of absolute agreement of the mean of $\mathrm{k}$ items. ${ }^{27}$

\section{4g Validity testing}

We will test for construct validity and external criterion validity using non-parametric spearman-rank correlations and generalized linear regression, with items added for this purpose as described above and shown in Appendix 1. We will use t-tests and ANOVA to test for known-groups validity. We will also examine inter-item and item-scale correlations and consider dropping items with low values.

Upon completion of statistical analysis, we will make final decisions about items to be included in the scales, taking results for measurement invariance, reliability, and validity into account. If revisions are deemed necessary based on the results of the statistical analyses, we will generate new items and/or revise items as needed.

\section{4h Measurement invariance assessment}

We will test for measurement invariance at both the group and item level. We will use multiple-group CFA to test for configural, metric, and scalar invariance across groups, comparing data from India and Uganda. ${ }^{28}$ We will then use IRT to test for uniform and non-uniform differential item functioning (DIF), examining results both visually and statistically. 2229

\section{Phase 3: Scale evaluation and further validation}

\subsection{Content validity assessment for new and modified items}

As in Phase 2, trained data collectors will conduct cognitive interviews to evaluate newly added items and translations prior to broader survey implementation. Team members will do a rapid analysis of data from the $\mathrm{Cls}$ and revise the survey instruments as needed.

\subsection{Survey participant selection in three sites}

We will administer cross-sectional surveys to a sample of respondents in three cities: Narsapur and Warangal (India) and Lusaka (Zambia). As in prior phases, these cities were selected based on the presence of existing CWIS programs.

As in Phase 2, we will calculate the sample size for Phase 3 with the goal of having at least 15 responses per item (i.e. multiplying the number of items in the longest scale by 15) for both EFA and CFA and then 
medRxiv preprint doi: https://doi.org/10.1101/2021.05.04.21256595; this version posted May 6, 2021. The copyright holder for this preprint (which was not certified by peer review) is the author/funder, who has granted medRxiv a license to display the preprint in perpetuity. It is made available under a CC-BY-NC-ND 4.0 International license .

adding $10 \%$ to allow for non-response. The sampling strategy, participant selection strategy, and inclusion criteria will remain the same as in Phase 2. Surveys will be implemented in the predominant local language(s).

\subsection{Data collection and management}

As in previous phases, enumerators will be recruited and given a five-day training. Data collection will follow the same procedures as in Phase 2, with enumerators obtaining consent, administering the full survey instrument in the local language(s) most appropriate to each location, and entering responses electronically on a tablet. As in Phase 2, the survey instrument will include all 15 scales and six indices, plus modules on demographics, water and sanitation access and behaviors, menstruation, and additional items to assess validity. In addition, we will assess mental health using the Center for Epidemiologic Studies Depressions Scale (CESD-10) and the Patient Health Questionnaire-4 (PHQ-4), well-being using the World Health Organization Well-Being Index (WHO-5), and life satisfaction using the Personal Wellbeing Index (PWI). Finally, we will add survey items related to COVID-19 to assess how sanitation-related behaviors and experiences may have been impacted by the pandemic.

\subsection{Statistical analysis}

For any scales with new or revised items, we will conduct CFAs to verify that the factor structure identified in Phase 2 is still optimal. Following the same procedures as Phase 2, we will use GRM IRT approaches to assess psychometric properties of the new and revised items within these scales. For all scales, we will then conduct CFAs to test the optimal factor structures identified in Phase 2. We will use the same fit indices and criteria described above to assess model fit. As in Phase 2, we will test for measurement invariance at both the group (city) and item level using multiple-group CFA and IRT methods; calculate the reliability coefficient, coefficient omega; and test for convergent, discriminant, and external criterion validity.

\section{Public involvement}

Public involvement in the ARISE scale development process occurs in every phase. While the conceptual model for the scales was determined a priori, and survey items were generated deductively, cognitive interviews are conducted in every phase to elicit the emic perspective of women in each research context. Participants in the cognitive interviews provide item-specific and overall comments and feedback, which leads to survey revision and refinement. This helps to ensure that the scales are reflective of participants' own priorities and experiences. In addition, the CWIS partners include public providers of sanitation services, such as national sanitation offices and city authorities. These key public stakeholders are invited to provide input on the survey and are involved in the development of a sampling strategy in each city to ensure that study results will be useful to them. Finally, the CWIS partners will also be asked for input on dissemination plans.

\section{Limitations}

Our survey instruments are specific to women in urban settings; adaptation and further validity testing is needed to develop instruments that can be administered with men and in peri-urban and rural settings. In addition, the survey instruments are focused on empowerment at the individual, household, and community levels. Therefore, they do not assess empowerment in markets (e.g. across the sanitation value chain) or in relation to policies and formal governance. Methodologically, best practices 
medRxiv preprint doi: https://doi.org/10.1101/2021.05.04.21256595; this version posted May 6, 2021. The copyright holder for this preprint (which was not certified by peer review) is the author/funder, who has granted medRxiv a license to display the preprint in perpetuity.

It is made available under a CC-BY-NC-ND 4.0 International license.

include using inductive methods (e.g. exploratory qualitative research) to guide item development, employing social network methods to assess social capital, and measuring time use (including in different seasons) as part of measuring empowerment related to time. ${ }^{13} 30$ Due to time and budget constraints and concerns about participant burden, we were not able to incorporate these recommended methods into our work.

\section{Ethics and dissemination}

\section{Ethics}

All participants provide oral or written consent to enumerators in their local language using a standardized script. Study activities in Phase 2 were reviewed and approved by Internal Review Boards (IRBs) at Emory University (USA; IRB 00110271), Azim Premji University (India; Ref. No.

2019/SOD/Faculty/5.1), and Makerere University (Uganda; Ref. No. 2019-038). Study activities for Phase 3 have been reviewed and approved by Internal Review Boards (IRBs) at Emory University (USA; IRB 00110271), the Indian Institute of Health Management and Research (India; IRB No. IRB/20202021/001), and ERES Converge (Zambia; Ref. No. 2020-oct-03).

\section{Dissemination}

The study team will share findings with CWIS partners and stakeholders to inform programming activities and will publish results in peer-reviewed journals. We will create training materials, webinars, and other guidance documents to support future use of the instruments. Data will be made open access via a data repository per BMGF guidelines. 
medRxiv preprint doi: https://doi.org/10.1101/2021.05.04.21256595; this version posted May 6, 2021. The copyright holder for this preprint (which was not certified by peer review) is the author/funder, who has granted medRxiv a license to display the preprint in perpetuity. It is made available under a CC-BY-NC-ND 4.0 International license .

\section{References}

1. (UNICEF); UNCSF, (WHO); WHO. Progress on household drinking water, sanitation and hygiene 2000 2017: special focus on inequalities. New York: UNICEF and WHO, 2019.

2. Clement F, Karki E. When Water Security Programmes Seek to Empower Women-A Case Study from Western Nepal. Water Security Across the Gender Divide: Springer 2018:151-69.

3. Leahy C, Winterford K, Nghiem T, et al. Transforming gender relations through water, sanitation, and hygiene programming and monitoring in Vietnam. Gender \& Development 2017;25(2):283-301.

4. Leder S, Clement F, Karki E. Reframing women's empowerment in water security programmes in Western Nepal. Gender \& Development 2017;25(2):235-51.

5. Richardson RA. Measuring Women's Empowerment: A Critical Review of Current Practices and Recommendations for Researchers. Social Indicators Research 2018;137(2):539-57. doi: 10.1007/s11205-017-1622-4

6. DeVellis RF. Overview. Scale development: theory and applications. Fourth ed. Los Angeles: SAGE Publications, Inc. 2017:17.

7. Van Eerdewijk A, Wong F, Vast C, et al. White Paper: A Conceptual Model of Women and Girls' Empowerment. Amsterdam: Royal Tropical Institute (KIT), 2017.

8. Hinkin TR. A brief tutorial on the development of measures for use in survey questionnaires. Organizational research methods 1998;1(1):104-21.

9. World Health Organization. Preamble to the Constitution of WHO as adopted by the International Health Conference, New York, 19 June - 22 July 1946; signed on 22 July 1946 by the representatives of 61 States (Official Records of WHO, no. 2, p. 100) and entered into force on 7 April 19481948 [cited 201701 Nov]. Available from: http://apps.who.int/gb/bd/PDF/bd47/EN/constitution-en.pdf?ua=1.

10. DeVellis RF. Content validity. Scale development: theory and applications. Fourth ed. Los Angeles: SAGE Publications, Inc. 2017:84-85.

11. Johanson GA, Brooks GP. Initial scale development: sample size for pilot studies. Educational and psychological measurement 2010;70(3):394-400.

12. Morgado FFR, Meireles JFF, Neves CM, et al. Scale development: ten main limitations and recommendations to improve future research practices. Psicologia: Reflexão e Crítica 2017;30(1):3. doi: 10.1186/s41155-016-0057-1

13. Boateng GO, Neilands TB, Frongillo EA, et al. Best practices for developing and validating scales for health, social, and behavioral research: a primer. Frontiers in public health 2018;6:149.

14. Bandalos DL, Finney SJ. Factor analysis: exploratory and confirmatory. In: Hancock GR, Mueller RO, eds. The reviewer's guide to quantitative methods in the social sciences. New York: Routledge 2010:93-114.

15. DeVellis RF. Factor analysis. Scale development: theory and applications. Fourth ed. Los Angeles: SAGE Publications, Inc. 2017:165-70.

16. Kline RB. Principles and practice of structural equation modeling. 3 ed. New York: The Guilford Press 2011:180-181.

17. Hooper D, Coughlan J, Mullen MR. Structural equation modelling: guidelines for determining model fit. The Electronic Journal of Business Research Methods 2008;6(1):53-60.

18. Toland MD. Practical guide to conducting an item response theory analysis. The Journal of Early Adolescence 2014;34(1):120-51.

19. Foster GC, Min H, Zickar MJ. Review of item response theory practices in organizational research: Lessons learned and paths forward. Organizational Research Methods 2017;20(3):465-86.

20. Desjardins CD, Bulut O. Item response theory for polytomous items. Handbook of educational measurement and psychometrics using R: CRC Press 2018:143-67. 
medRxiv preprint doi: https://doi.org/10.1101/2021.05.04.21256595; this version posted May 6, 2021. The copyright holder for this preprint (which was not certified by peer review) is the author/funder, who has granted medRxiv a license to display the preprint in perpetuity. It is made available under a CC-BY-NC-ND 4.0 International license .

21. DeVellis RF. An overview of item response theory. Scale development: theory and applications. Fourth ed. Los Angeles: SAGE Publications, Inc. 2017:213-24.

22. Finch WH, French BF. Polytomous item response theory models. Latent variable modeling with $\mathrm{R}$. New York: Routledge 2015:217-30.

23. Hayes AF, Coutts JJ. Use Omega Rather than Cronbach's Alpha for Estimating Reliability. But.... Communication Methods and Measures 2020:1-24.

24. Trizano-Hermosilla I, Alvarado JM. Best alternatives to Cronbach's alpha reliability in realistic conditions: Congeneric and asymmetrical measurements. Frontiers in psychology 2016;7:769.

25. Kelley K, Pornprasertmanit S. Confidence intervals for population reliability coefficients: Evaluation of methods, recommendations, and software for composite measures. Psychological methods 2016;21(1):69.

26. Kline RB. Principles and practice of structural equation modeling: Guilford publications 2015.

27. Koo TK, Li MY. A Guideline of Selecting and Reporting Intraclass Correlation Coefficients for Reliability Research. J Chiropr Med 2016;15(2):155-63. doi: 10.1016/j.jcm.2016.02.012 [published Online First: 2016/03/31]

28. Dimitrov DM. Confirmatory factor analysis. Statistical methods for validation of assessment scale data in counseling and related fields. Alexandria, VA: John Wiley \& Sons 2014:95-137.

29. Edwards MC, Edelen MO. Special topics in item response theory. The SAGE handbook of quantitative methods in psychology 2009:178-98.

30. Bill \& Melinda Gates Foundation. What gets measured matters: A methods note for measuring women and girls' empowerment: Bill \& Melinda Gates Foundation.

\section{Authors' contributions}

SSS and BC conceptualized the study and obtained funding. All authors contributed to developing ARISE scale items. SSS and AC wrote the manuscript. AC and MP trained data collection teams and oversaw data collection for Phases 1 and 2. SM developed the data analysis plan, with input from SSS. All authors critically reviewed and approved the final draft of the manuscript.

\section{Funding statement}

This work was supported by the Bill \& Melinda Gates Foundation grant number OPP1191625.

\section{Competing interests statement}

None declared.

\section{Acknowledgements}

We are grateful to Deepa Karthykeyan, Kun Zhang, Arjun Sharma, Jacinta Ngabo, Ritah Kobusingye, and Josephine Kalenda Goma of Athena Infonomics, as well as Vinod Ramanarayanan and Srishty Arun of Civic Fulcrum, for leading study activities in each country, to all members of the data collection teams, and to the CWIS partners for their input and support. We wish to thank our panel of expert reviewers (listed in alphabetical order): Jenala Chipungu (Centre for Infectious Disease Research, Zambia); Mary Kincaid (IRIS Group); Arundati Muralidharan (WaterAid India); and Lucero Quiroga (Stanford University). We thank CS Sharada Prasad and Ajilé Owens for additional project contributions. 